\title{
Polyacrylonitrile-based fiber modified with thiosemicarbazide by microwave irradiation and its adsorption behavior for $\mathrm{Cd}(\mathrm{II})$ and $\mathrm{Pb}$ (II)
}

Sheng Deng ${ }^{\mathrm{a}, \mathrm{b}}$, Peng Wang ${ }^{\mathrm{a}, \mathrm{b}, *}$, Guangshan Zhang ${ }^{\mathrm{b}, * *}$, Yuan Dou ${ }^{\mathrm{c}}$

${ }^{a}$ State Key Laboratory of Urban Water Resource and Environment, Harbin 150090, PR China

${ }^{b}$ School of Municipal and Environmental Engineering, Harbin Institute of Technology, Harbin 150090, PR China

${ }^{c}$ Shanxi Research Academy of Environmental Science, Taiyuan 030027, PR China

*Corresponding author. Tel.: +86-451-86283557; Fax: +86-451-86283557.

**Corresponding author.

E-mail addresses: pwang73@ @ip.sina.com (P. Wang), gszhanghit@ gmail.com (G.S. Zhang)

(C) 2016. This manuscript version is made available under the Elsevier user license http://www.elsevier.com/open-access/userlicense/1.0/ 


\begin{abstract}
:
A novel thiosemicarbazide modified adsorbent (PANMw-TSC) based on polyacrylonitrile fiber was successfully synthesized under microwave irradiation, which was applied for the uptake of $\mathrm{Cd}(\mathrm{II})$ and $\mathrm{Pb}$ (II) from aqueous solution subsequently. Microwave irradiation method is a new approach to achieve the modification and it turns out that just a 30 min process is enough for the anchoring of functional groups in the fiber matrix. The surface characterization was performed by fourier transform infrared spectroscopy (FT-IR), scanning electron microscopy (SEM) elemental analysis (EA) and thermogravimetric analysis (TGA), indicating that the modification was successfully accomplished. Batch adsorption experiments including equilibrium isotherms, kinetics and the effects of $\mathrm{pH}$ and temperature on the adsorption of $\mathrm{Cd}(\mathrm{II})$ and $\mathrm{Pb}(\mathrm{II})$ were systematically studied. Among three kinetic models, the pseudo-second-order kinetic model provides the best correlation for the process. The nonlinear resolution of the Langmuir isotherm equation has been found to show the closest fit to the equilibrium date. Thermodynamic parameters, involving $\Delta G, \Delta H$ and $\Delta S$ were also calculated from graphical interpretation of the experimental data, which suggest that metal ions adsorption onto PAN $\mathrm{MW}_{\mathrm{W}}$-TSC fibers is spontaneous and exothermic. Regeneration of PANMw-TSC fibers loaded with metal ions was efficiently done with $0.5 \mathrm{M} \mathrm{HNO}_{3}$, by which the investigated adsorbent could be used reproductively for five times with a small decrease in sorption capacity. The feasible preparation of PANMw-TSC fibers with high adsorption capacities opens a new perspective in the potential application for wastewater treatment.
\end{abstract}

Keywords: Microwave irradiation; Polyacrylonitrile fiber; Adsorption; Cadimum; Lead. 


\section{Introduction}

Nowadays, with the rapid development of industry, heavy metals have been abundantly discharged into the environment through industrial wastewater, which has become a worldwide environmental threat due to their non-biodegradability and carcinogenicity $[1,2]$. Discharged toxic metals typically including cadmium and lead could be accumulated into human body through food chains, causing serious diseases and disorders even at low concentrations [3, 4]. Cadimum, for example, is associated with a higher incidence of nephrotoxic effects while lead causes kidney damage, anaemia and detriment to the reproductive system. Thus, it is critical to remove $\mathrm{Cd}(\mathrm{II})$ and $\mathrm{Pb}(\mathrm{II})$ from wastewater in the perspective of environment and health. Several technologies and processes have been developed and applied for the removal of heavy metal ions from different aqueous solutions, such as chemical precipitation, ion exchange, membrane separation and electrochemical treatment [5-7]. Whereas, few satisfactory removal results could be achieved by the above-mentioned techniques on account of their low efficiency, high cost, disposal of sludge and sometimes might bring secondary pollution into the environment. Comparatively, adsorption technology with chelating ligands has received considerable attention due to its remarkable simplicity, high efficiency and availability of different adsorbents. Among various absorbents such as chitosan [8], activated carbon [9], silica nanocomposite and magnetite particles $[10,11]$, the absorbents based on polyacrylonitrile fiber (PANF) possess many desirable superiorities in solvent resistance, thermal and mechanical stability. The raw PANF shows no metal binding ability towards metal ions, nevertheless, the ability can be activated subsequently by modified with manifold low-molecular weight ligands $[12,13]$. Xiong et al. [14] reported that the 2-amino-1,3,4-thiadiazole functionalized PANF containing $\mathrm{N}$ and $\mathrm{S}$ atoms can be used for the selective adsorption of $\mathrm{Hg}$ (II) from mixed metal solutions. Zhao et al. [15] found that phosphorylate PAN nanofiber mat exhibit high adsorption performance towards $\mathrm{Pb}^{2+}, \mathrm{Cu}^{2+}, \mathrm{Ag}^{+}$and $\mathrm{Cd}^{2+}$ ions. According to the principle of hard and soft acids and bases, sulfur-containing groups are regarded as soft bases and therefore it is 
reasonable to use sulfur functionalized PANF to interact with such soft acids like $\mathrm{Cd}(\mathrm{II})$ and $\mathrm{Pb}(\mathrm{II})$ through a coordinate bond in the side chain of the polymer.

In recent years, microwave (MW) irradiation, as an alternative method, has been utilized in graft copolymerization in substitution of conventional heating methods due to its ability to ensure rapid and uniform heating in chemical reaction [16]. Basically, MW irradiation can penetrate the material and supply energy while heating can be initiated by transferring electromagnetic energy to thermal energy efficiently which results in volumetric heating [17]. Consequently, the processing time of the reaction was reduced and the product quality was enhanced. In our recent report, the iminodiacetic acid (IDA) functionalized chelating fiber was prepared by MW irradiation method which displayed a high adsorption efficiency for $\mathrm{Cu}$ (II) and $\mathrm{Hg}$ (II) [18].

In the present study, we prepared a sulfur-bearing adsorbent based on PANF in two step graft modification process through MW irradiation method. The obtained fibrous material was systematically explored as adsorbent for removal of $\mathrm{Cd}(\mathrm{II})$ and $\mathrm{Pb}$ (II) from aqueous solution by batch adsorption experiments. To further understand the adsorption process, the adsorption kinetics, isotherms and the thermodynamic properties of the adsorption of $\mathrm{Cd}(\mathrm{II})$ and $\mathrm{Pb}(\mathrm{II})$ on the synthetic fiber were also clarified. Moreover, the recovery of $\mathrm{Cd}(\mathrm{II})$ and $\mathrm{Pb}(\mathrm{II})$ and reusability of the adsorbent were investigated.

\section{Experimental}

\subsection{Materials and methods}

The polyacrylonitrile fiber (PANF) made by $100 \%$ acrylonitrile was purchased from Beijing Rongnai Industry Material Co., Ltd. (Beijing, PR China). Diethylenetriamine (DETA), thiosemicarbazide (TSC), N,N-dimethylformamide (DMF) were all supplied by Aladdin Chemical Reagent Co., Ltd. (Shanghai, PR China). Cadmium ion (500 $\left.\mathrm{mg} \cdot \mathrm{L}^{-1}\right)$ and lead ion $\left(500 \mathrm{mg} \cdot \mathrm{L}^{-1}\right)$ solution were prepared by dissolving appropriate amount of $\mathrm{CdCl}_{2} \cdot 2.5 \mathrm{H}_{2} \mathrm{O}$ and $\mathrm{Pb}\left(\mathrm{NO}_{3}\right)_{2}$ (Sinopharm Group Chemical Reagent Co., Ltd., Shanghai, PR China) in deionized water, respectively. 


\subsection{Crosslinking reaction of PANF}

The PANF (1.0 g), DETA $(40 \mathrm{~mL})$ and deionized water $(20 \mathrm{~mL})$ were added into a $250 \mathrm{~mL}$ round bottomed flask and then ultrasonic treated for $5 \mathrm{~min}$. The reaction was carried out in MW reactor (COOPLEX-E with output power $1200 \mathrm{~W}$, purchased from Preekem Scientific Instruments Co., Ltd, China) and the parameters of time and temperature were set up at $15 \mathrm{~min}$ and $388 \mathrm{~K}$, respectively. The external and internal feature of the MW reactor are illustrated in Fig. S1 in supporting information (SI). After reaction, the product was washed with anhydrous ethanol and thermal deionized water until neutral, suction filtered, and dried in a vacuum oven at $343 \mathrm{~K}$ overnight. The crosslinked PAN fibers were named as PANMw-DETA. The grafting percentage $(G P \%)$ was calculated by gravimetry through following equation:

$$
G P \%=\frac{m_{1}-m_{0}}{m_{0}} \times 100 \%
$$

where $m_{0}$ and $m_{1}$ are the weights of raw polyacrylonitrile fiber and PANMW-DETA, respectively.

\subsection{Modification of PAN $\mathrm{MW}_{\mathrm{W}} \mathrm{DETA}$}

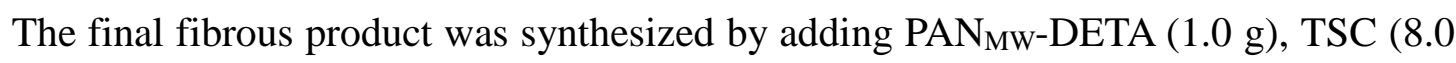
g), DMF (100 mL) into a $250 \mathrm{~mL}$ round bottomed flask. The reaction was refluxed for $15 \mathrm{~min}$ at $398 \mathrm{~K}$ under continuous mechanical stirring in MW reactor. Then the modified fibers were removed and washed with anhydrous ethanol and thermal deionized water until neutral, suction filtered and dried in a vacuum oven at $343 \mathrm{~K}$ overnight. Due to the slightly side effects in the modification process by MW irradiation, the DMF solvent could be used repeatedly for at least 10 times. The modified fibers grafted TSC were named as PAN $\mathrm{MW}$-TSC.

Schematic presentation for the synthetic steps of the PANMw-TSC is shown in Scheme 1 . 


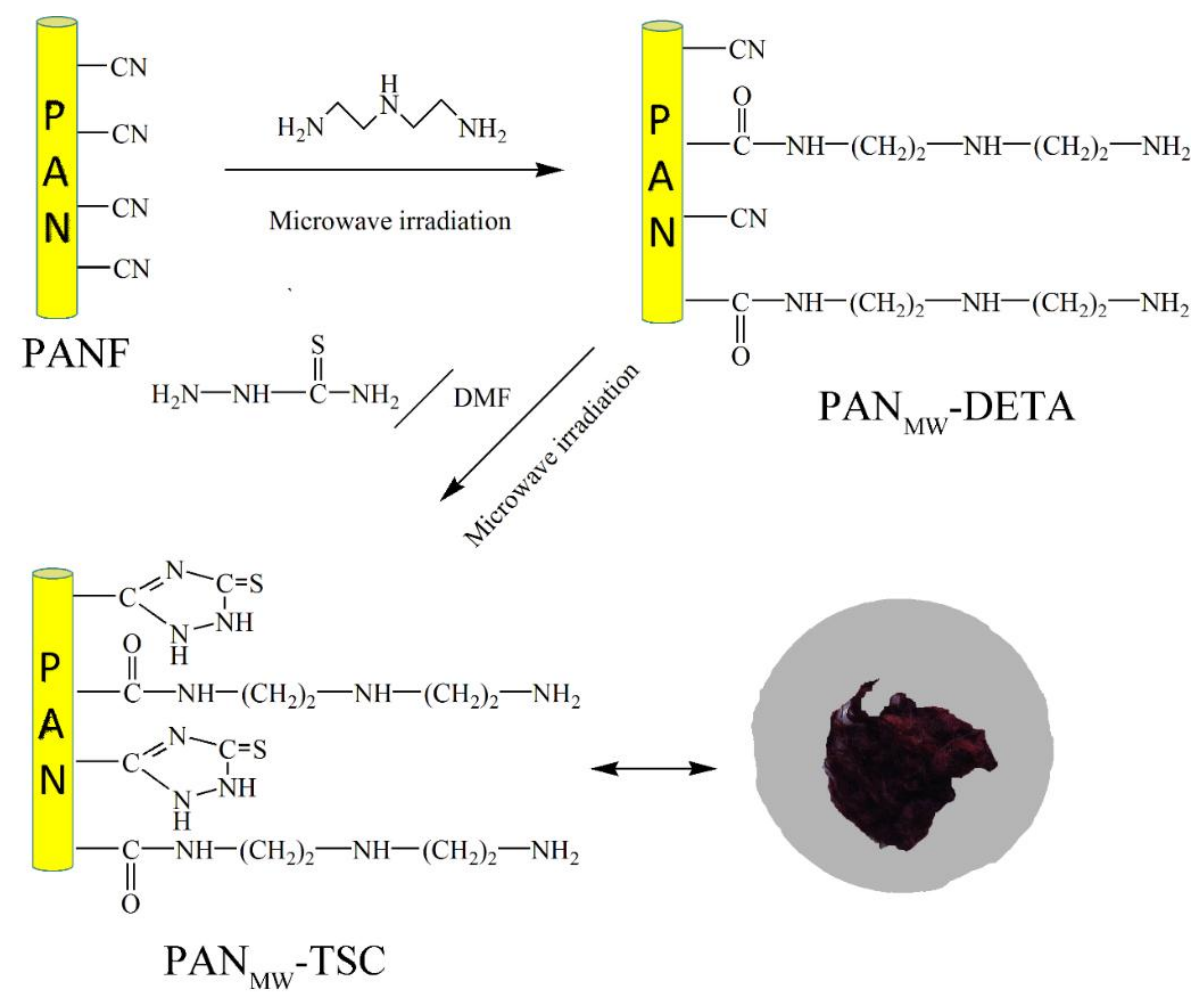

Scheme 1. Synthesis routine of PAN $\mathrm{MW}_{\mathrm{M}}$-TSC based on polyacrylonitrile fiber.

\subsection{Characterization and analysis}

The concentration of metal ions was determined using an inductively coupled plasma optimal emission spectrometer (ICP-OES; Perkin-Elmer Optimal 8300). Fourier transform infrared spectroscopy (FT-IR) experiments of PAN $\mathrm{MW}_{\mathrm{MW}}$-TSC were performed via a FT-IR spectrometer (Perkin-Elmer spectrum 100), and the spectra was recorded in the wave number ranging from 400 to $4000 \mathrm{~cm}^{-1}$. Surface morphology of $\mathrm{PAN}_{\mathrm{MW}}$-TSC was observed by scanning electron microscope-energy dispersive X-ray spectroscopy (SEM/EDX; FEI QUANTA 200). Thermogravimetric analysis (TGA) in a range of temperature $30-500^{\circ} \mathrm{C}$ by $10^{\circ} \mathrm{C} \mathrm{min}{ }^{-1}$ under the protection of nitrogen on a TGA instrument (METTLER TOLEDO; TGA/SDTA851).

\subsection{Batch adsorption experiments}

The prepared PAN $\mathrm{MW}_{\mathrm{M}} \mathrm{TSC}$ fibers were used as adsorbents for the removal of $\mathrm{Cd}(\mathrm{II})$ and $\mathrm{Pb}(\mathrm{II})$ from aqueous system. All batch adsorption experiments were performed on a model SHA-C shaker (Ronghua instrumental manufactory Co., Ltd., China) with a shaking speed of $100 \mathrm{rpm}$. The adsorption kinetics of the two metals were carried out with the initial concentration of $300 \mathrm{mg} \cdot \mathrm{L}^{-1}$ at $298 \mathrm{~K}$ and lasted for $180 \mathrm{~min}$. 
Adsorption isotherm for each heavy metal were conducted with initial concentration ranging from 20 to $300 \mathrm{mg} \cdot \mathrm{L}^{-1}$ at $288 \mathrm{~K}, 293 \mathrm{~K}, 298 \mathrm{~K}$, respectively. The effect of $\mathrm{pH}$ value on adsorption was studied as $\mathrm{pH}$ ranged from 3 to 6.4 with the initial concentration of $300 \mathrm{mg} \cdot \mathrm{L}^{-1}$. Citric acid/sodium citrate buffer solution was used to adjust the $\mathrm{pH}$ value. The concentration of the metal ions in solution was determined by ICP-OES spectrometer. The adsorption capacity of the metal ion adsorbed onto each sample, $q_{\mathrm{e}}\left(\mathrm{mg} \cdot \mathrm{g}^{-1}\right)$, was calculated on the basis of the following equation:

$$
q_{\mathrm{e}}=\frac{\left(C_{0}-C_{\mathrm{e}}\right) V}{m}
$$

Where $C_{0}$ and $C_{\mathrm{e}}$ are the initial and the equilibrium concentration of the metal ions in the test solution $\left(\mathrm{mg} \cdot \mathrm{L}^{-1}\right)$, respectively, $V$ is the volume of the testing solution (L), and $m$ is the weight of the adsorbent ( $\mathrm{g}$ ). For regeneration of the fiber adsorbents, the fibers were washing with $0.5 \mathrm{M} \mathrm{HNO}_{3}$ and then washed several times with deionized water. The adsorption/desorption cycle was repeated five times using the same PAN ${ }_{M W}$-TSC fibers.

\section{Result and discussion}

\subsection{Preparation and characterization of $\mathrm{PAN}_{\mathrm{MW}}$-TSC fibers}

In our previous work, we have demonstrated highly time and energy efficient synthesis of IDA functionalized chelating fiber by using MW irradiation method [18], in which water acts as the mainly MW adsorber. To obtain TSC modified fibers in the present research, water was also introduced as the solvent in the reaction mixture firstly, but there is nearly no TSC immobilized on the fiber after the reaction. According to some previous researches $[19,20]$, DMF was suitable for the grafting reaction of TSC into different substrates such as active carbon and PVDF membrane. During MW irradiation process, the ability of a specific substance to convert electromagnetic energy into heat at a given frequency and temperature is determined by the so-called loss factor $\tan \delta$. Solvent with a high $\tan \delta$ value is required for efficient absorption, and consequently, for rapid heating [21]. Compared with water, DMF possess more sufficient ability of energy transforming on account of its higher $\tan \delta$ value. In application of DMF as solvent instead of water in the reaction under 
MW irradiation, the GP\% of PAN $\mathrm{MW}_{\mathrm{M}}$-TSC fibers reached $35 \%$ in $15 \mathrm{~min}$ at $398 \mathrm{~K}$ and carmine fibers were obtained finally.

Meanwhile, for comparison of conventional heating with MW irradiation method, the immobilization of TSC experiment was performed at thermostatic magnetic heating agitator (CL-3, Gongyi City Yuhua Instrument Co., Ltd., China) under the same conditions and the grafting results are shown in Table 1. It is obviously to observe that the functionalization rate was dramatically accelerated and the outcome products by MW irradiation gained nearly nine times as much as those by conventional heating. The unique heat way and mass transfer characteristics of MW irradiation might be the reason of fast modification and high yield of PANMw-TSC fibers [22].

\section{Table 1}

Comparison of different heating types for preparation of PAN $\mathrm{Mw}_{\mathrm{M}}$-TSC fiber.

\begin{tabular}{ccc}
\hline TSC Modification & MW irradiation & Conventional heating \\
\hline$G P \%$ & 35 & 4
\end{tabular}

$\begin{array}{lll}\text { Time (h) } & 0.25 & 12\end{array}$

The FT-IR spectra of the raw PANF, PAN $\mathrm{MW}_{\mathrm{W}}$ DETA and PAN $\mathrm{MW}_{\mathrm{M}}$-TSC fibers are shown in Fig. 1. A sharp and distinct adsorption band at $2243 \mathrm{~cm}^{-1}$ in PANF,

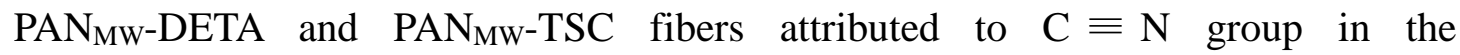
polyacrylonitrile fiber. Although the fiber was claimed to be made of $100 \%$ acrylonitrile, the adsorption at $1683 \mathrm{~cm}^{-1}$ still confirmed the existence of methyl acrylate or methyl methacrylate [23]. After crosslinked by DETA, the adsorption intensity of $\mathrm{C} \equiv \mathrm{N}$ group reduced and disappeared entirely at the peak of $1683 \mathrm{~cm}^{-1}$. Moreover, two new peaks at $1566 \mathrm{~cm}^{-1}(\mathrm{C}=\mathrm{O})$ and $1651 \mathrm{~cm}^{-1}\left(-\mathrm{NH}_{2}\right)$ appeared, suggesting the happening of the crosslinking reaction [24]. In the infrared spectrum of PANMw-TSC fibers, three new peaks occurred. The band at $1372 \mathrm{~cm}^{-1}$ and $1507 \mathrm{~cm}^{-1}$ attribute to stretching vibrations of $\mathrm{C}=\mathrm{S}$ and $\mathrm{N}-\mathrm{C}=\mathrm{S}[25,26]$. The band at $1640 \mathrm{~cm}^{-1}$ indicated the presence of $\mathrm{C}=\mathrm{N}$ bond [27]. These results are all coordinated with the Scheme. 1 presented above.

The results of the elemental analysis of C, N, O, S of the fibers are given in Table 2. The $\mathrm{C}$ value of PANMw-DETA and PANMw-TSC fibers decreased after the 
crosslinking and modification, which may attribute to the lower carbon content of DETA and TSC. Due to the hydrolysis of $\mathrm{C} \equiv \mathrm{N}$ group into $\mathrm{O}=\mathrm{C}-\mathrm{OH}$, the $\mathrm{N}$ value decline was found in PAN ${ }_{M w}$-DETA fibers. About $10.21 \%$ of sulfur content newly appeared in PAN $\mathrm{MW}_{\mathrm{MW}}$-TSC fibers, indicated that the thiosemicarbazide group has been successfully attached onto it and it coordinated to the results of FT-IR. Both FT-IR spectrum and EA analysis confirmed that the TSC functional group has been anchored expectantly on the surface of PANMw-TSC fibers.

The morphologies of fibers obtaining from different reaction steps were observed by SEM and the results are shown in Fig. 2. It can be seen that the surface of PANF was smooth and neat, barely with crack on it. Inspiringly, after crosslink reaction, the smooth surface of PANF fibers was substituted with creased appearance and the fibers were shrunk simultaneously. Compared with PANF, both PAN $\mathrm{MW}_{\mathrm{M}}$-DETA and PAN ${ }_{M W}-T S C$ fibers showed an increase in diameter which may due to the introducing of DETA and TSC chains onto the fiber [28]. Additionally, all the fibers kept well in shape and did not show any serious cracks or degradation while the color altered from faint yellow to crimson. Therefore, the immobilization of DETA and TSC was expected to change the properties of the pure fiber and then affect metal ion adsorption.

The thermal stabilities of the raw PANF, PAN $\mathrm{MW}_{\mathrm{M}}$-DETA and PAN $\mathrm{NW}_{\mathrm{M}}$-TSC fibers were performed and compared, and the results are shown in Fig. 3. The PAN $\mathrm{MW}_{\mathrm{MW}}$-DEA and PAN ${ }_{M W}$-TSC fibers exhibited three mainly steps transient of weight loss at temperature (i) $100^{\circ} \mathrm{C}$, (ii) $280^{\circ} \mathrm{C}$, and (iii) $450^{\circ} \mathrm{C}$, which are ascribed to (i) evaporation of moisture and residue on the polymer, (ii) decomposition of the grafted functional groups, and (iii) degradation of the PANF backbone, respectively. Comparatively, the PANF showed tiny gravity loss under $280^{\circ} \mathrm{C}$ and the residue weight was higher than both PAN $\mathrm{MW}_{\mathrm{W}}$-DETA and PANMw-TSC fibers. These results all indicated that the modification was successfully took place on the fiber. 


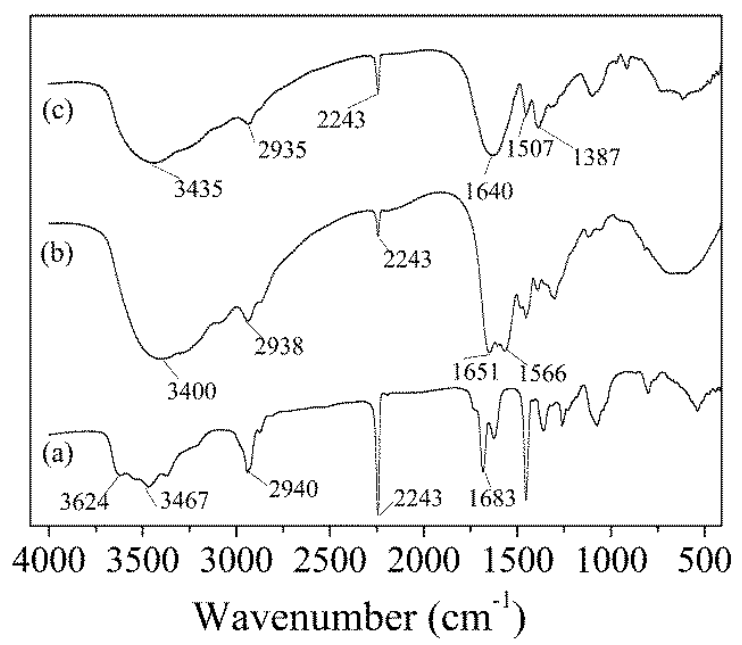

Fig. 1. FT-IR spectrum of: (a) PANF, (b) PAN $\mathrm{MW}_{\mathrm{M}}-\mathrm{DETA}$ and (c) PAN $\mathrm{PAW}_{\mathrm{M}}-\mathrm{TSC}$.

Table 2

The dates of element analysis of PAN-Raw fiber, PAN ${ }_{M w}$-DETA and PAN MW-TSC.

\begin{tabular}{cccccc}
\hline Sample & \multicolumn{3}{c}{ Element content $(\%)$} & Grafting ratio (\%) \\
\cline { 2 - 5 } & $\mathrm{C}$ & $\mathrm{N}$ & $\mathrm{H}$ & $\mathrm{S}$ & \\
\hline PAN & 64.97 & 27.53 & 5.41 & & \\
PAN $_{\mathrm{MW}}$-DETA & 55.26 & 25.89 & 7.85 & & 45.33 \\
PAN $_{\text {MW }}$-TSC & 46.43 & 25.36 & 6.17 & 10.21 & 13.86 \\
\hline
\end{tabular}

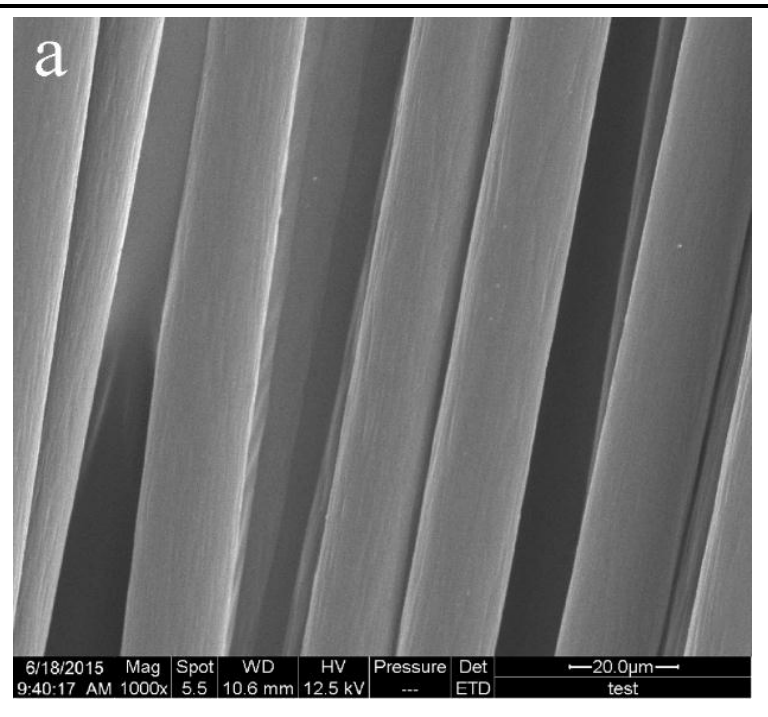



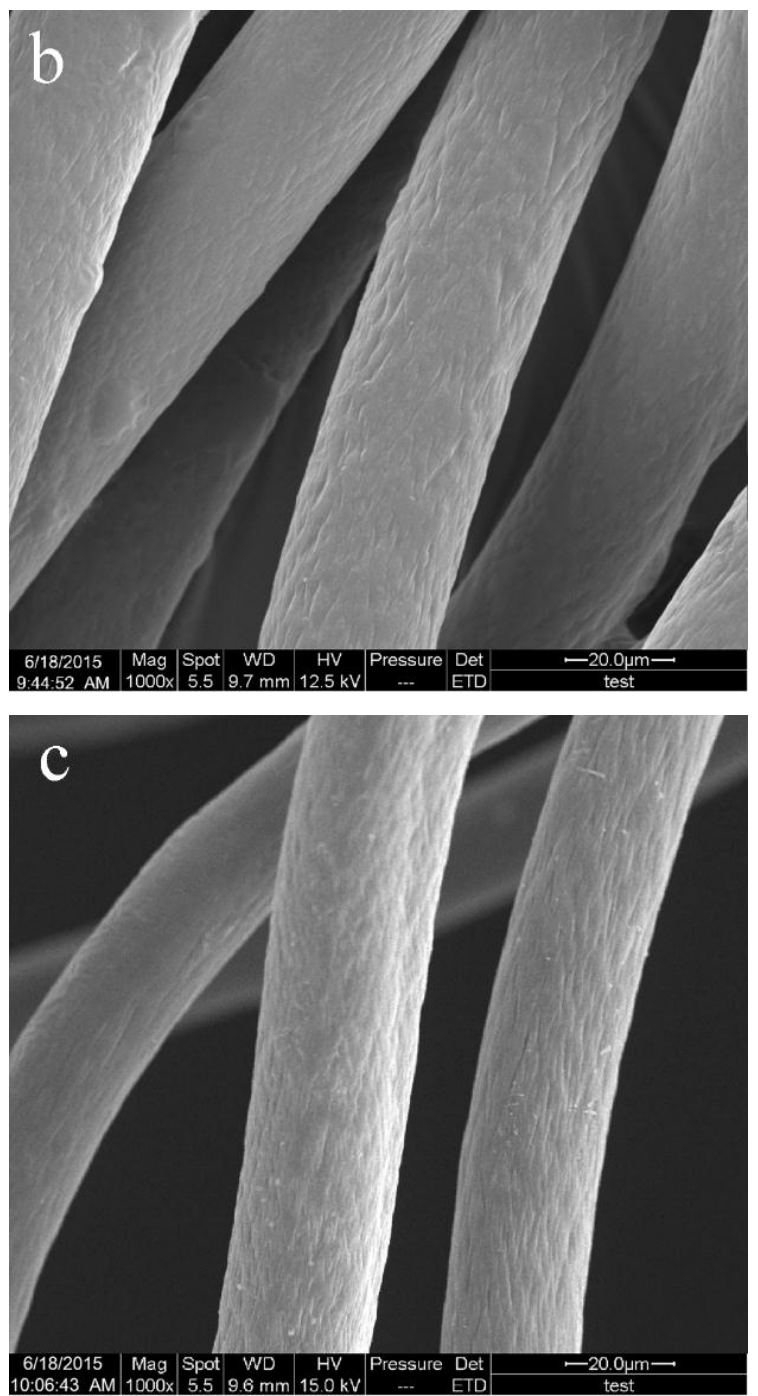

Fig. 2. SEM images of: (a) PANF, (b) PAN $\mathrm{MW}_{\mathrm{W}}$-DETA and (c) PAN $\mathrm{MW}_{\mathrm{M}}-\mathrm{TSC}$.

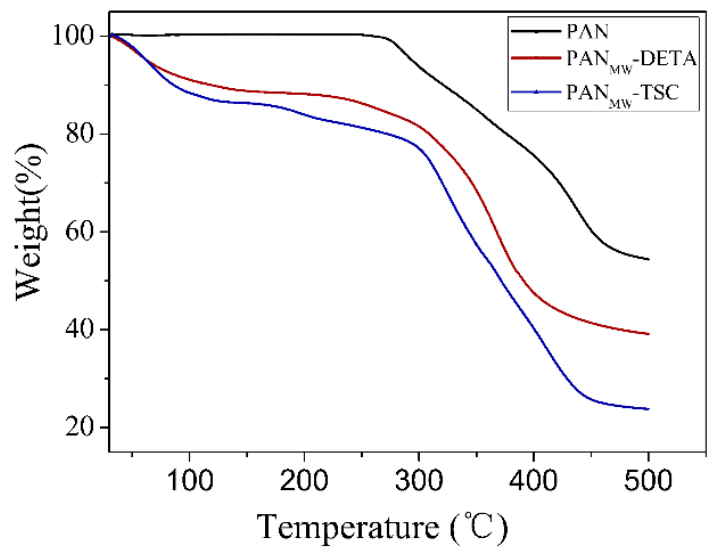

Fig. 3. TGA curves of PANF, PAN $\mathrm{MW}_{\mathrm{W}}$-DETA and PAN $\mathrm{PW}_{\mathrm{M}}$-TSC fibers.

\subsection{Adsorption behaviors}

3.2.1. Effect of $\mathrm{pH}$ on $\mathrm{Cd}(\mathrm{II})$ and $\mathrm{Pb}(\mathrm{II})$ adsorption

The $\mathrm{pH}$ value of the solution has been regarded as the most important factor during 
adsorption process. In this perspective, the experiments were carried out at different $\mathrm{pH}$ conditions ranged from 2 to 6.4. The $\mathrm{pH}$ values were accessed using the $\mathrm{pH}$ meter (PHSJ-4F, Shanghai Yidian Co., Ltd., China) with pH electrode. Whereas, beyond $\mathrm{pH}$ 6.4 , the tests were not proceeded due to the formation of cadmium hydroxide and lead hydroxide $[29,30]$.

Apparently, as presented in Fig. 4, the adsorption capacities on PAN $\mathrm{MW}_{\mathrm{W}} \mathrm{TSC}$ fibers were highly $\mathrm{pH}$ dependent and the maximum capacities of $\mathrm{Cd}(\mathrm{II})$ and $\mathrm{Pb}(\mathrm{II})$ increased steadily to $1.42 \mathrm{mmol} \cdot \mathrm{g}^{-1}$ and $0.95 \mathrm{mmol} \cdot \mathrm{g}^{-1}$ at $\mathrm{pH}$ value of 6.4 , respectively. At this $\mathrm{pH}$, the modified fibers acquired negatively charged surface which enhanced the electrostatic attraction between the fibers and metal ions followed by chelation [31]. The observed low uptakes at lower $\mathrm{pH}$ were attribute to the protonation of the subgroup of PAN $\mathrm{MW}$-TSC (-NH-), along with the existence of large amount of $\mathrm{H}^{+}$in the solution, which prevented metal ions from approaching and adhering onto the fibers. These negative impacts were descended as the increasing of the $\mathrm{pH}$ which led to higher amount of capacities in PAN $\mathrm{MW}_{\mathrm{M}}$-TSC fibers. Normally, the $\mathrm{pH}$ of naturel water polluted by metal ions was around 7 which indicated that PAN $\mathrm{MW}_{\mathrm{M}}$-TSC fibers could be effectively used as suitable adsorbents for the removal of $\mathrm{Cd}(\mathrm{II})$ and $\mathrm{Pb}(\mathrm{II})$ from the polluted water.

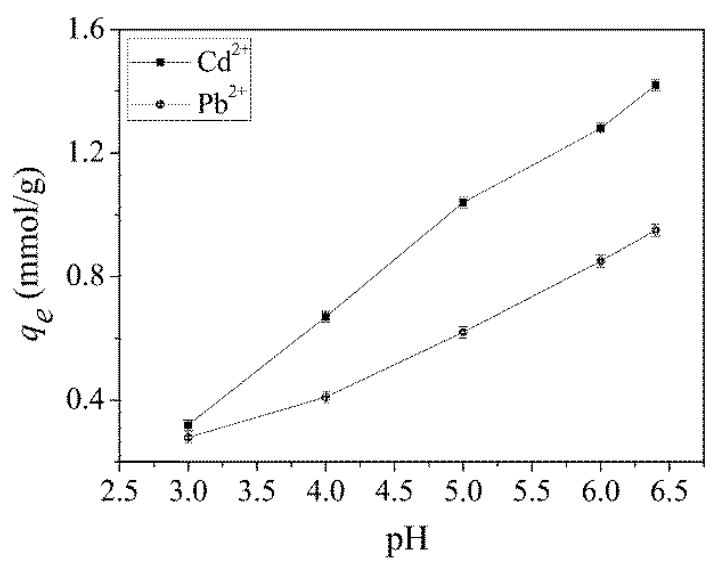

Fig. 4. Effect of $\mathrm{pH}$ on the adsorption capacity of $\mathrm{PAN}_{\mathrm{Mw}}-\mathrm{TSC}$ for $\mathrm{Cd}(\mathrm{II})$ and $\mathrm{Pb}(\mathrm{II})$ at $298 \mathrm{~K}$.

\subsubsection{Adsorption kinetics}

Kinetic studies of $\mathrm{Cd}(\mathrm{II})$ and $\mathrm{Pb}(\mathrm{II})$ were carried out at $298 \mathrm{~K}$ and $\mathrm{pH} 6.4$, and the dynamic adsorption results are presented in Fig. 5. It can be seen that the 
adsorption process for these two metal ions were rapid which reached its half saturation at just $30 \mathrm{~min}$ and nearly $90 \%$ saturation at $60 \mathrm{~min}$. The adsorption equilibrium was attained in $180 \mathrm{~min}$, approximately. The fast adsorption rate may attribute to the fiber state of the adsorbent, in which the active adsorption sites were mainly located at the outer surface and thus the diffusion resistance of mass transfer during adsorption process would be negligible [32].
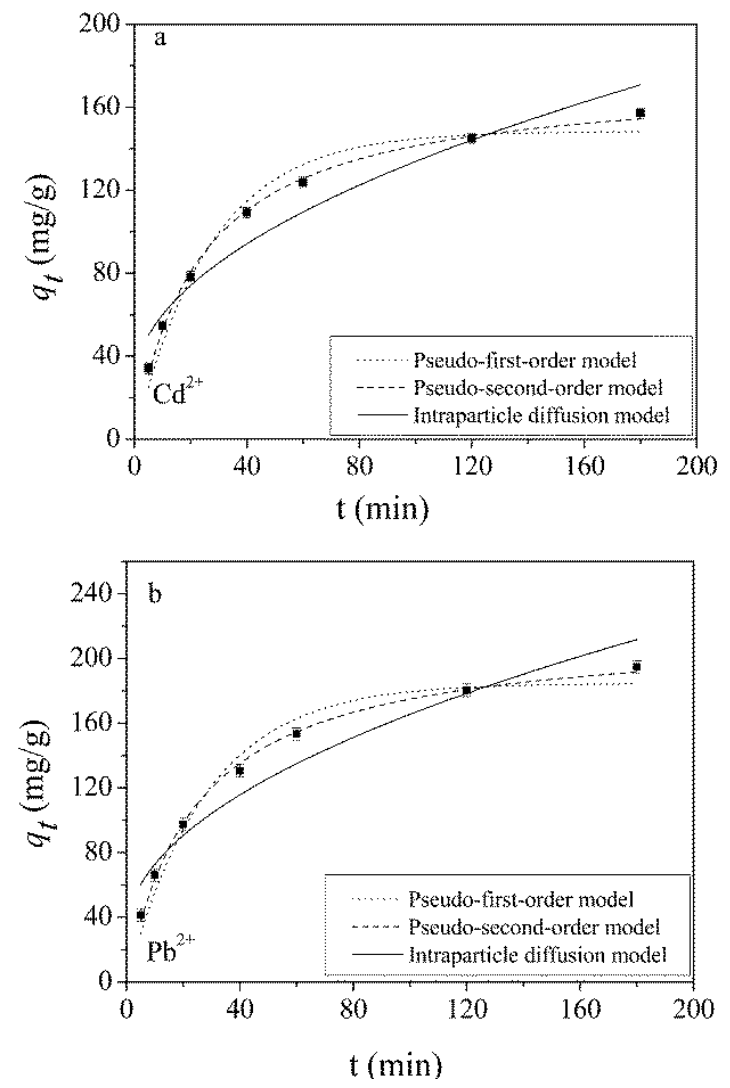

Fig. 5. Adsorption kinetics curve of $\mathrm{Cd}(\mathrm{II})$ and $\mathrm{Pb}$ (II) on $\mathrm{PAN}_{\mathrm{Mw}}-\mathrm{TSC}$ at $298 \mathrm{~K}$ and $\mathrm{pH}$ 6.4.

The applicability of the pseudo-first-order, pseudo-second-order and intraparticle diffusion models were tested for the adsorption of $\mathrm{Cd}(\mathrm{II})$ and $\mathrm{Pb}$ (II) onto $\mathrm{PAN}_{\mathrm{MW}}$-TSC fibers. The best fit model was selected based on both linear regression correlation coefficient $\left(R^{2}\right)$ and the calculated $q_{\mathrm{e}}$ values. These three equations describe the kinetics of adsorption process are expressed as follows [33]:

$$
\begin{gathered}
q_{\mathrm{t}}=q_{\mathrm{e}}\left(1-e^{-k_{1} t}\right) \\
q_{\mathrm{t}}=\frac{q_{\mathrm{e}}{ }^{2} k_{2} t}{1+q_{\mathrm{e}} k_{2} t} \\
q_{\mathrm{t}=} k_{3} t^{0.5}
\end{gathered}
$$

where $q_{\mathrm{e}}$ and $q_{\mathrm{t}}$ are the amount of heavy metal ions adsorbed $\left(\mathrm{mg} \cdot \mathrm{g}^{-1}\right)$ at equilibrium and at time $\mathrm{t}(\mathrm{min})$, respectively, while $k_{1}, k_{2}$ and $k_{3}$ are the rate constants of the 
pseudo-first-order model $\left(\mathrm{min}^{-1}\right)$, pseudo-second-order model $\left(\mathrm{mg} \cdot \mathrm{g}^{-1} \cdot \mathrm{min}^{-1}\right)$ and intraparticle diffusion model $\left(\mathrm{mg} \cdot \mathrm{g}^{-1} \cdot \mathrm{min}^{-1 / 2}\right)$.

As a statistical tool for the best explanation of an adsorption system, the nonlinear chi-square test has been utilized by judging the sum squares differences between the experimental and the calculated data with each squared difference is divided by its corresponding value $[34,35]$.

$$
\chi^{2}=\sum_{i=1}^{n} \frac{\left(q_{e, c a l}-q_{e, e x p}\right)^{2}}{q_{e, \exp }}
$$

where $q_{\mathrm{e}, \text { cal }}\left(q_{\mathrm{e}, \text { calculated }}\right)$ equilibrium capacity obtained by calculated from model $\left(\mathrm{mg} \cdot \mathrm{g}^{-1}\right)$ and $q_{\mathrm{e}, \text { exp. }}\left(q_{\mathrm{e}, \text { experimental }}\right)$ was the equilibrium capacity from the experimental data $\left(\mathrm{mg} \cdot \mathrm{g}^{-1}\right)$. The value of $\chi^{2}$ calculated from the equation represents the similarity between the data from model and the data from experiment test. A small $\chi^{2}$ value indicated similarities, while a larger number represents variation of the experimental data [36].

Kinetic parameters and Chi-square values from all kinetic models have been calculated and listed in Table 3. It was observed that the calculated $q_{\mathrm{e}, \text { cal }}$ values of both $\mathrm{Cd}(\mathrm{II})$ and $\mathrm{Pb}(\mathrm{II})$ obtained from the pseudo-second-order model are different from the experimental $q_{\mathrm{e} \text { exp. }}$ values when compared with calculations from the pseudo-first-order model, which possibly resulted from the imprecise sampling and inaccurate testing within the error range. The $\chi^{2}$ value of pseudo-second-order model for metal ions are the smallest which followed by those of pseudo-first-order model and intraparticle diffusion model, respectively. Additionally, according to the $R^{2}$ values, the pseudo-second-order model fits the experimental kinetic data better than the pseudo-first-order model and intraparticle diffusion model, suggesting that the adsorbent system can be well-described by the pseudo-second-order model. The pseudo-second-order model was developed on the assumption that the rate-determining step may be chemisorption promoted by covalent forces through electron sharing between adsorbent and adsorbate [37]. Thus, the result suggested that the adsorption of two metal ions on the PANMw-TSC fibers was mainly controlled by the chemically reactive adsorption. 
Table 3

Kinetic model constants for the adsorption of $\mathrm{Cd}(\mathrm{II})$ and $\mathrm{Pb}(\mathrm{II})$ onto PANMw-TSC fibers.

\begin{tabular}{|c|c|c|c|c|c|c|c|c|c|c|c|c|}
\hline \multirow{3}{*}{$\begin{array}{l}\text { Metal } \\
\text { ions }\end{array}$} & \multirow{3}{*}{$\begin{array}{c}q_{\mathrm{e}, \mathrm{exp}} \\
\left(\mathrm{mg} \cdot \mathrm{g}^{-1}\right)\end{array}$} & \multicolumn{4}{|c|}{ pseudo-first-order model } & \multicolumn{4}{|c|}{ pseudo-second-order model } & \multicolumn{3}{|c|}{ intraparticle diffusion model } \\
\hline & & $q_{\mathrm{e}, \mathrm{cal}}$ & $k_{1}$ & $R^{2}$ & $\chi^{2}$ & $q_{\mathrm{e}, \mathrm{cal}}$ & $k_{2} \times 10^{4}$ & $R^{2}$ & $\chi^{2}$ & $k_{3}$ & $R^{2}$ & $\chi^{2}$ \\
\hline & & $\left(\mathrm{mg} \cdot \mathrm{g}^{-1}\right)$ & $\left(\min ^{-1}\right)$ & & & $\left(\mathrm{mg} \cdot \mathrm{g}^{-1}\right)$ & $\left(\mathrm{mg} \cdot \mathrm{g}^{-1} \cdot \min ^{-1}\right)$ & & & $\left(\mathrm{mg} \cdot \mathrm{g}^{-1} \cdot \mathrm{min}^{-1 / 2}\right)$ & & \\
\hline $\mathrm{Cd}$ (II) & 157.04 & 148.36 & 0.037 & 0.9678 & 10.95 & 174.22 & 2.47 & 0.9968 & 1.091 & 10.8 & 0.9138 & 29.33 \\
\hline $\mathrm{Pb}$ (II) & 194.77 & 184.63 & 0.036 & 0.9665 & 7.349 & 217.41 & 1.89 & 0.9962 & 0.829 & 13.5 & 0.922 & 17.12 \\
\hline
\end{tabular}

$q_{\mathrm{e}, \text { exp. }}, q_{\mathrm{e}, \text { experimental }} ; q_{\mathrm{e}, \text { cal. }}, q_{\mathrm{e}, \text { calculated }}$

\subsubsection{Adsorption isotherms}

To examine the effect of initial concentration of metal ions on the adsorption capacity, the adsorption isotherms of $\mathrm{Cd}(\mathrm{II})$ and $\mathrm{Pb}(\mathrm{II})$ at $288 \mathrm{~K}, 293 \mathrm{~K}, 298 \mathrm{~K}$ were undertaken to simulate the metal uptake by adsorbents. The $\mathrm{pH}$ value of $\mathrm{Cd}(\mathrm{II})$ and $\mathrm{Pb}$ (II) were adjusted to 6.4 by citric acid/sodium citrate buffer solution. The results shown in Fig. 6 indicated that the adsorption capacities of $\mathrm{Cd}(\mathrm{II})$ and $\mathrm{Pb}(\mathrm{II})$ improved with the increase of Initial concentration of metal ions until maximum adsorption were reached gradually.

The Langmuir and Freundlich isotherm models are the most frequently used models to describe and analyze the adsorption isotherms. The Langmuir isotherm model is derived to assume surface homogeneity of the adsorbent, such as identical active sites, monolayer adsorption and no interaction between the adsorbed species. The Freundlich isotherm model proposed based on the assumption of surface heterogeneous due to the diversity of the adsorption sites or the diverse nature of the metal ion-adsorbed, free, or hydrolyzed species. The Langmuir and Freundlich equations can be expressed as follows [38]:

$$
\begin{gathered}
q_{\mathrm{e}}=\frac{q_{\mathrm{m}} K_{\mathrm{d}} C_{\mathrm{e}}}{1+K_{\mathrm{d}} C_{\mathrm{e}}} \\
q_{\mathrm{e}}=K_{\mathrm{f}} C_{e}^{\frac{1}{n}}
\end{gathered}
$$

where $q_{e}$ is the amount of metal ion adsorbed at equilibrium by the adsorbent $\left(\mathrm{mmol} \cdot \mathrm{g}^{-1}\right), C_{e}$ is the equilibrium concentration $\left(\mathrm{mmol} \cdot \mathrm{L}^{-1}\right), q_{\mathrm{m}}$ is theoretical saturation adsorption capacity $\left(\mathrm{mmol} \cdot \mathrm{g}^{-1}\right), K_{\mathrm{d}}\left(\mathrm{L} \cdot \mathrm{mmol}^{-1}\right)$ is the equilibrium Langmuir constant, $K_{\mathrm{f}}\left(\mathrm{mmol} \cdot \mathrm{g}^{-1}\right)$ and $n$ are constants representing the adsorption capacity and 
intensity of adsorption.

The fitting of equilibrium data at different temperature by Langmuir and Freundlich models was conducted and the results are presented in Fig. 6 and Table 4. As illustrated in Fig. 6, the equilibrium data are very well represented by Langmuir model and it can be observed from the parameters listed in Table 4 that the adsorption equilibrium data well fits Langmuir model with correlation coefficient values $R^{2}>$ 0.99. Additionally, the maximum adsorption capacities of $\mathrm{Cd}(\mathrm{II})$ and $\mathrm{Pb}(\mathrm{II})$ by PAN ${ }_{M W}$-TSC fibers according to Langmuir model are highly agreed with the experimental value in each temperature. The better fit of equilibrium data by Langmuir isotherm model confirms the monolayer coverage of metal ions into the homogenous surface of the adsorbents.

According to the Langmuir fitting, the maximum adsorption capacity was 1.47 $\mathrm{mmol} \cdot \mathrm{g}^{-1}$ for $\mathrm{Cd}(\mathrm{II})$ and $1.01 \mathrm{mmol} \cdot \mathrm{g}^{-1}$ for $\mathrm{Pb}(\mathrm{II})$, respectively. The higher tendency toward $\mathrm{Cd}(\mathrm{II})$ than that for $\mathrm{Pb}(\mathrm{II})$ may be attributed to the anchoring of sulfur atom by the modification of thiosemicarbazide. Cadmium is considered as a soft Lewis acid due to its high polarizability, and according to the theory of hard and soft acids and bases, soft acid coordinate more strongly with ligands that have soft donor atoms [39]. This result was also proved by comparing the adsorption capacities between PAN $_{M W}$-DETA and PAN $\mathrm{MW}_{\mathrm{M}}$-TSC fibers in Table $\mathrm{S} 1$ in supporting information.
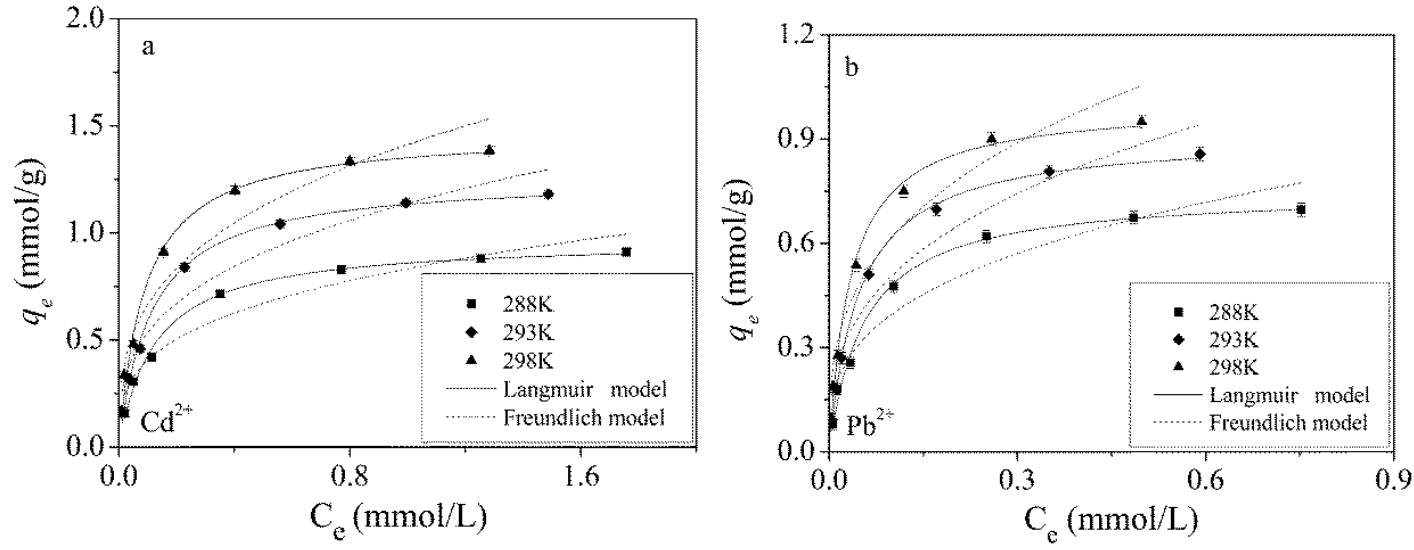

Fig. 6. Adsorption equilibrium curve of $\mathrm{Cd}(\mathrm{II})$ and $\mathrm{Pb}(\mathrm{II})$ on $\mathrm{PAN}_{\mathrm{MW}}-\mathrm{TSC}$ at $288 \mathrm{~K}, 293 \mathrm{~K}$ and $298 \mathrm{~K}$ and $\mathrm{pH} 6.4$. 


\section{Table 4}

Adsorption isotherm parameters for the adsorption of $\mathrm{Cd}(\mathrm{II})$ and $\mathrm{Pb}(\mathrm{II})$ on $\mathrm{PAN}_{\mathrm{MW}}-\mathrm{TSC}$ at $288 \mathrm{~K}$, $293 \mathrm{~K}$ and $298 \mathrm{~K}$.

\begin{tabular}{cccccccc}
\hline \multirow{2}{*}{ Metal } & $\mathrm{T}(\mathrm{K})$ & \multicolumn{3}{c}{ Langmuir parameters } & \multicolumn{4}{c}{ Freundlich parameters } \\
\cline { 3 - 8 } ions & & $q_{\mathrm{m} .}\left(\mathrm{mmol} \cdot \mathrm{g}^{-1}\right)$ & $K_{\mathrm{d}}\left(\mathrm{L} \cdot \mathrm{mmol}^{-1}\right)$ & $R^{2}$ & $n$ & $K_{\mathrm{f}}\left(\mathrm{mmol} \cdot \mathrm{g}^{-1}\right)$ & $R^{2}$ \\
\hline \multirow{3}{*}{$\mathrm{Cd}(\mathrm{II})$} & 288 & 0.967 & 7.96 & 0.9916 & 3.23 & 0.833 & 0.9317 \\
& 293 & 1.26 & 8.83 & 0.9924 & 3.13 & 1.13 & 0.9387 \\
& 298 & 1.47 & 11.07 & 0.9901 & 3.12 & 1.41 & 0.9324 \\
\cline { 2 - 8 } & 288 & 0.749 & 17.72 & 0.9913 & 3.01 & 0.851 & 0.9241 \\
$\mathrm{~Pb}(\mathrm{II})$ & 293 & 0.913 & 20.97 & 0.9977 & 2.86 & 1.12 & 0.9393 \\
& 298 & 1.01 & 28.97 & 0.9918 & 2.99 & 1.33 & 0.9403 \\
\hline
\end{tabular}

\subsubsection{Thermodynamic analysis}

An insight towards the spontaneity and energetics involved in the interaction between the modified fibers and the metal ions can be best explained through the Gibbs free energy change $(\Delta G)$, entropy $(\Delta S)$ and enthalpy $(\Delta H)$ which are determined by the following equations:

$$
\begin{aligned}
& \Delta G=-R T L n K_{\mathrm{d}} \\
& L n k=\frac{\Delta S}{R}-\frac{\Delta H}{R T}
\end{aligned}
$$

where $K_{\mathrm{d}}$ is the adsorption equilibrium constant obtained from Langmuir model, $R$ is the universal gas constant $\left(8.314 \mathrm{~J} \cdot \mathrm{mol}^{-1} \cdot \mathrm{K}^{-1}\right), T$ is the temperature $(\mathrm{K})$. The values of $\Delta H$ and $\Delta S$ could be obtained as the slope and intercept from a linear plot between Lnk versus $1 / T$.

The obtained thermodynamic parameters for the adsorption process are presented in Table 5. The transport of metal ions from the solution phase to the adsorbent is partially dominated by the concentration gradient across the adsorbent-solution interphase which is reflected in the free energy difference. The increase in absolute $\Delta G$ value as temperature rising indicated that the adsorption process becomes more favorable at higher temperature and the positive values of $\Delta H$ and $\Delta S$ for the adsorption of $\mathrm{Cd}(\mathrm{II})$ and $\mathrm{Pb}(\mathrm{II})$ demonstrated the endothermic nature of this process, along with an increased randomness at the solid-liquid interface [40]. 
Table 5

Thermodynamic parameters for the adsorption of $\mathrm{Cd}(\mathrm{II})$ and $\mathrm{Pb}(\mathrm{II})$ on $\mathrm{PAN}_{\mathrm{MW}}-\mathrm{TSC}$.

\begin{tabular}{cccccc}
\hline \multirow{2}{*}{ Metal ions } & $\Delta H$ & $\Delta S$ & \multicolumn{3}{c}{$\Delta G\left(\mathrm{~kJ} \cdot \mathrm{mol}^{-1}\right)$} \\
\cline { 4 - 6 } & $\left(\mathrm{kJ} \cdot \mathrm{mol}^{-1}\right)$ & $\left(\mathrm{J} \cdot \mathrm{mol}^{-1} \cdot \mathrm{k}\right)$ & $283 \mathrm{~K}$ & $293 \mathrm{~K}$ & $303 \mathrm{~K}$ \\
\hline $\mathrm{Cd}(\mathrm{II})$ & 23.48 & 99 & -4.96 & -5.31 & -5.95 \\
$\mathrm{~Pb}(\mathrm{II})$ & 30.03 & 150 & -6.88 & -7.41 & -8.34 \\
\hline
\end{tabular}

3.2.5. Desorption experiment and reusability

In order to economize the application of adsorbent, it is imperative to evaluate the regeneration ability of PAN $_{M W}$-TSC fibers in the adsorption process. Thus, sorption-desorption cycles were performed repeatedly to examine the reusability and metal recovery efficiency of PANMw-TSC fibers. In the present study, $0.5 \mathrm{M} \mathrm{HNO}_{3}$ solution solution was used to desorb the $\mathrm{Cd}(\mathrm{II})$ and $\mathrm{Pb}(\mathrm{II})$ adsorbed by $\mathrm{PAN}_{\mathrm{MW}}$-TSC fibers and this process repeated for five sorption-desorption cycles. Fig. 7 summarizes desorption efficiency for the five cycles. As depicted in Fig. 7, the desorption efficiency of heavy metal ions decreased slightly as the regeneration cycles progressed, which indicated that $0.5 \mathrm{M} \mathrm{HNO}_{3}$ solution can effectively desorb from PAN ${ }_{M W}$-TSC fibers. Moreover, at the end of the fifth cycle, the fibers still retained more than $85 \%$ of its original adsorption capacity for the metal ions which indicated that no appreciable loss in capacities over the five studied cycles. The results illustrated that PAN $\mathrm{MW}_{\mathrm{W}}$-TSC fiber was expected to be a promising adsorbent for fast removal of $\mathrm{Cd}(\mathrm{II})$ and $\mathrm{Pb}$ (II) from aqueous solution, especially in emergency disposal of heavy metal pollution accidents.

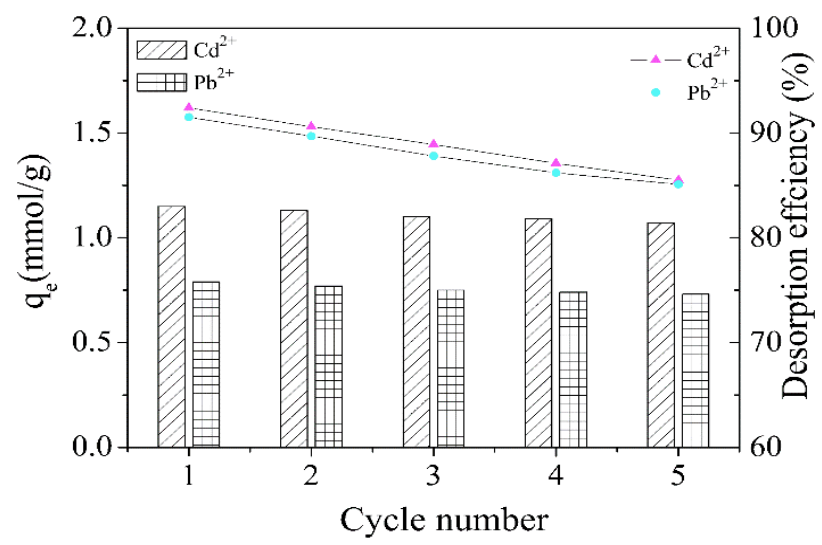

Fig. 7. Different cycles on the desorption efficiency of $\mathrm{Cd}(\mathrm{II})$ and $\mathrm{Pb}(\mathrm{II})$ by $\mathrm{PAN}_{\mathrm{MW}}$-TSC fibers. 3.3. Comparison with other fibrous adsorbents

Compared with the reported fibrous adsorbents in Table 6 which were prepared 
through conventional heating, the adsorption capacities of PANMw-TSC fibers for these two metal ions were higher, and the duration of functionalization process decreased incredibly by using MW irradiation. The consumed time declined from 5-29 $\mathrm{h}$ to $0.5 \mathrm{~h}$ with higher grafting rate of $\mathrm{N}$ and $\mathrm{S}$ atoms onto the fibers which both took effects in the adsorption process [41, 42].

The observed acceleration and high grafting rate of PAN $\mathrm{MW}_{\mathrm{W}} \mathrm{TSC}$ fibers might attribute to the combination of thermal and non-thermal effect of MW irradiation. In other words, MW irradiation is instantaneous which leads to shorter start-up and rapid internal heating during the functionalization process [43-45]. Importantly, as we mentioned above, the non-thermal effect of MW irradiation was taking effects through the distinct results from the conventionally heated counterpart at the same measured reaction conditions [46].

\section{Table 6}

Comparison of PAN $\mathrm{MW}_{\mathrm{MW}}$-TSC fiber adsorption capacities with other fibrous adsorbents.

\begin{tabular}{|c|c|c|c|c|c|c|}
\hline \multirow[t]{2}{*}{ Adsorbents } & \multirow[t]{2}{*}{$\begin{array}{l}\text { Reaction time } \\
\text { (h) }\end{array}$} & \multicolumn{2}{|c|}{$\begin{array}{l}\text { Adsorption capacity } \\
\left(\mathrm{mmol} \cdot \mathrm{g}^{-1}\right)\end{array}$} & \multicolumn{2}{|c|}{$\mathrm{pH}$} & \multirow[t]{2}{*}{ Reference } \\
\hline & & $\mathrm{Cd}(\mathrm{II})$ & $\mathrm{Pb}(\mathrm{II})$ & $\mathrm{Cd}(\mathrm{II})$ & $\mathrm{Cd}(\mathrm{II})$ & \\
\hline $\mathrm{PAN} / \mathrm{PPy} / \mathrm{MnO}_{2}$ nanofiber & 12 & - & 0.83 & - & 6.0 & [47] \\
\hline $\begin{array}{c}\text { phosphorylated PAN-based } \\
\text { nanofiber }\end{array}$ & 29 & 0.17 & 0.47 & 6.0 & 6.0 & [15] \\
\hline $\mathrm{PAN}_{\mathrm{ac}} \mathrm{F}$ & 12 & 1.11 & - & 6.0 & - & [48] \\
\hline $\begin{array}{c}\text { poly(p-phenylene terephthalamide) } \\
\text { fibers }\end{array}$ & 8 & - & 0.087 & - & 5.0 & [49] \\
\hline functionalized polyacrylonitrile & $5-29$ & - & 0.85 & - & 5.0 & {$[50]$} \\
\hline chitosan nanofibril & - & 0.54 & 0.57 & 5.0 & 5.0 & [51] \\
\hline cellulose fiber & 24 & 0.77 & 0.93 & 6.0 & 5.7 & {$[52]$} \\
\hline $\mathrm{PAN}_{\mathrm{MW}}$-TSC fiber & 0.75 & 1.47 & 1.01 & 6.4 & 6.4 & $\begin{array}{l}\text { Present } \\
\text { study }\end{array}$ \\
\hline
\end{tabular}




\section{Conclusions}

This work has shown that MW irradiation provided an effective approach to immobilize thiosemicarbazide onto polyacrylonitrile fiber, and the results indicated that the PAN $\mathrm{MW}_{\mathrm{M}}$-TSC fibers obtained by MW possessed remarkable accelerated duration and high grafting rate. Thermal and non-thermal effect were convinced to make efforts in these two grafting steps. The adsorption capacities of the obtained PAN $_{M W}$-TSC fibers for $\mathrm{Cd}(\mathrm{II})$ and $\mathrm{Pb}(\mathrm{II})$ were found to be significantly improved with increasing $\mathrm{pH}$ value and reached the top at $\mathrm{pH}$ 6.4. The adsorption kinetics were found to follow pseudo-second-order model and the equilibrium data followed Langmuir isotherm model. The maximum adsorption capacities for $\mathrm{Cd}(\mathrm{II})$ and $\mathrm{Pb}$ (II) were $1.47 \mathrm{mmol} \cdot \mathrm{g}^{-1}$ and $1.01 \mathrm{mmol} \cdot \mathrm{g}^{-1}$, respectively, according to Langmuir model. The high adsorption capacity of PAN $\mathrm{NW}_{\mathrm{M}}$-TSC fibers was attributed to the introduction of nitrogen and sulfur atom onto the surface of the adsorbent. The adsorption thermodynamics indicated that the adsorption process is spontaneous and endothermic. The regeneration experiments showed that the fabricated adsorbent had a good stability and reusability within five times regeneration. Overall, MW irradiation is a fascinating and promising tool for the preparation of functional fibrous adsorbent, which exhibits excellent prospect in heavy metal ions wastewater treatment.

\section{Acknowledgements}

The work was supported by State Key Laboratory of Urban Water Resource and Environment (Harbin Institute of Technology) (2015DX03), Fundamental Research Funds for the Central Universities (HIT. NSRIF. 201671) and National Science Foundation for Post-doctoral Scientists of China (2014M561356). 


\section{References}

[1] J. Gong, T. Liu, X. Wang, X. Hu, L. Zhang, Efficient Removal of Heavy Metal Ions from Aqueous Systems with the Assembly of Anisotropic Layered Double Hydroxide Nanocrystals@Carbon Nanosphere, Environ. Sci. Technol. 45 (2011) 6181-6187.

[2] Q. Yuan, N. Li, Y. Chi, W. Geng, W. Yan, Y. Zhao, X. Li, B. Dong, Effect of large pore size of multifunctional mesoporous microsphere on removal of heavy metal ions, J. Hazard. Mater.. 254-255 (2013) 157-165.

[3] M.S. Mansour, M.E. Ossman, H.A. Farag, Removal of Cd (II) ion from waste water by adsorption onto polyaniline coated on sawdust, Desalination. 272 (2011) 301-305.

[4] C.P. Wang, J.Z. Wu, H.W. Sun, T. Wang, H.B. Liu, Y. Chang, Adsorption of Pb(II) Ion from Aqueous Solutions by Tourmaline as a Novel Adsorbent, Industrial \& Engineering Chemistry Research. 50 (2011) 8515-8523.

[5] C. Ahmed Basha, N.S. Bhadrinarayana, N. Anantharaman, K.M. Meera Sheriffa Begum, Heavy metal removal from copper smelting effluent using electrochemical cylindrical flow reactor, J. Hazard. Mater.. 152 (2008) 71-78.

[6] F. Kayaci, Z. Aytac, T. Uyar, Surface modification of electrospun polyester nanofibers with cyclodextrin polymer for the removal of phenanthrene from aqueous solution, J. Hazard. Mater. 261 (2013) 286-294.

[7] V.V.T. Padil, M. Černík, Poly (vinyl alcohol)/gum karaya electrospun plasma treated membrane for the removal of nanoparticles ( $\mathrm{Au}, \mathrm{Ag}, \mathrm{Pt}, \mathrm{CuO}$ and $\mathrm{Fe} 3 \mathrm{O} 4)$ from aqueous solutions, J. Hazard. Mater. 287 (2015) 102-110.

[8] R. Karthik, S. Meenakshi, Removal of $\mathrm{Pb}(\mathrm{II})$ and $\mathrm{Cd}(\mathrm{II})$ ions from aqueous solution using polyaniline grafted chitosan, Chem. Eng. J. 263 (2015) 168-177.

[9] F. Asadi, H. Shariatmadari, N. Mirghaffari, Modification of rice hull and sawdust sorptive characteristics for remove heavy metals from synthetic solutions and wastewater, J. Hazard. Mater. 154 (2008) 451-458.

[10] L. Chu, C. Liu, G. Zhou, R. Xu, Y. Tang, Z. Zeng, S. Luo, A double network gel as low cost and easy recycle adsorbent: Highly efficient removal of $\mathrm{Cd}(\mathrm{II})$ and $\mathrm{Pb}(\mathrm{II})$ pollutants from wastewater, $\mathrm{J}$. Hazard. Mater. 300 (2015) 153-160.

[11] X. Guo, B. Du, Q. Wei, J. Yang, L. Hu, L. Yan, W. Xu, Synthesis of amino functionalized magnetic graphenes composite material and its application to remove $\mathrm{Cr}(\mathrm{VI}), \mathrm{Pb}$ (II), $\mathrm{Hg}$ (II), $\mathrm{Cd}$ (II) and $\mathrm{Ni}$ (II) from contaminated water, J. Hazard. Mater. 278 (2014) 211-220.

[12] Y.G. Ko, Y.J. Chun, C.H. Kim, U.S. Choi, Removal of $\mathrm{Cu}(\mathrm{II})$ and $\mathrm{Cr}(\mathrm{VI})$ ions from aqueous solution using chelating fiber packed column: Equilibrium and kinetic studies, J. Hazard. Mater. 194 (2011) 92-99.

[13] A.F. Shaaban, D.A. Fadel, A.A. Mahmoud, M.A. Elkomy, S.M. Elbahy, Synthesis and characterization of dithiocarbamate chelating resin and its adsorption performance toward $\mathrm{Hg}(\mathrm{II}), \mathrm{Cd}$ (II) and $\mathrm{Pb}$ (II) by batch and fixed-bed column methods, J. Environ. Chem. Eng. 1 (2013) 208-217.

[14] C. Xiong, Y. Li, G. Wang, L. Fang, S. Zhou, C. Yao, Q. Chen, X. Zheng, D. Qi, Y. Fu, Y. Zhu, Selective removal of $\mathrm{Hg}(\mathrm{II})$ with polyacrylonitrile-2-amino-1,3,4-thiadiazole chelating resin: Batch and column study, Chem. Eng. J. 259 (2015) 257-265.

[15] R. Zhao, X. Li, B. Sun, M. Shen, X. Tan, Y. Ding, Z. Jiang, C. Wang, Preparation of phosphorylated polyacrylonitrile-based nanofiber mat and its application for heavy metal ion removal, 
Chem. Eng. J. 268 (2015) 290-299.

[16] S. Das, A.K. Mukhopadhyay, S. Datta, D. Basu, Prospects of microwave processing: An overview, Bull. Mater. Sci. 32 (2009) 1-13.

[17] J.D. Moseley, C.O. Kappe, A critical assessment of the greenness and energy efficiency of microwave-assisted organic synthesis, Green Chemistry. 13 (2011) 794-806.

[18] S. Deng, G. Zhang, X. Wang, T. Zheng, P. Wang, Preparation and performance of polyacrylonitrile fiber functionalized with iminodiacetic acid under microwave irradiation for adsorption of $\mathrm{Cu}(\mathrm{II})$ and Hg(II), Chem. Eng. J. 276 (2015) 349-357.

[19] R. Gao, Z. Hu, X. Chang, Q. He, L. Zhang, Z. Tu, J. Shi, Chemically modified activated carbon with 1-acylthiosemicarbazide for selective solid-phase extraction and preconcentration of trace $\mathrm{Cu}(\mathrm{II})$, $\mathrm{Hg}$ (II) and Pb(II) from water samples, J. Hazard. Mater. 172 (2009) 324-329.

[20] H. Li, X. Wang, L. Cao, X. Zhang, C. Yang, Gold-recovery PVDF membrane functionalized with thiosemicarbazide, Chem. Eng. J. 280 (2015) 399-408.

[21] C. Gabriel, S. Gabriel, E. H. Grant, E. H. Grant, B. S. J. Halstead, D. Michael P. Mingos, Dielectric parameters relevant to microwave dielectric heating, Chemical Society Reviews. 27 (1998) 213-224.

[22] N. Wang, P. Wang, Study and application status of microwave in organic wastewater treatment - A review, Chem. Eng. J. 283 (2016) 193-214.

[23] X. Xing, H. Yang, M. Tao, W. Zhang, An overwhelmingly selective colorimetric sensor for $\mathrm{Ag}^{+}$ using a simple modified polyacrylonitrile fiber, J. Hazard. Mater. 297 (2015) 207-216.

[24] G. Hong, X. Li, L. Shen, M. Wang, C. Wang, X. Yu, X. Wang, High recovery of lead ions from aminated polyacrylonitrile nanofibrous affinity membranes with micro/nano structure, J. Hazard. Mater 295 (2015) 161-169.

[25] M. Monier, D.A. Abdel-Latif, Modification and characterization of PET fibers for fast removal of $\mathrm{Hg}(\mathrm{II}), \mathrm{Cu}(\mathrm{II})$ and $\mathrm{Co}(\mathrm{II})$ metal ions from aqueous solutions, J. Hazard. Mater. 250-251 (2013) $122-130$

[26] L. Bai, H. Hu, W. Fu, J. Wan, X. Cheng, L. Zhuge, L. Xiong, Q. Chen, Synthesis of a novel silica-supported dithiocarbamate adsorbent and its properties for the removal of heavy metal ions, J. Hazard. Mater. 195 (2011) 261-275.

[27] Y. Zhang, Y. Chen, C. Wang, Y. Wei, Immobilization of 5-aminopyridine-2-tetrazole on cross-linked polystyrene for the preparation of a new adsorbent to remove heavy metal ions from aqueous solution, J. Hazard. Mater. 276 (2014) 129-137.

[28] M. Monier, D.A. Abdel-Latif, Preparation of cross-linked magnetic chitosan-phenylthiourea resin for adsorption of $\mathrm{Hg}(\mathrm{II}), \mathrm{Cd}(\mathrm{II})$ and $\mathrm{Zn}(\mathrm{II})$ ions from aqueous solutions, J. Hazard. Mater. 209-210 (2012) 240-249.

[29] P. Wang, M. Du, H. Zhu, S. Bao, T. Yang, M. Zou, Structure regulation of silica nanotubes and their adsorption behaviors for heavy metal ions: $\mathrm{pH}$ effect, kinetics, isotherms and mechanism, J. Hazard. Mater. 286 (2015) 533-544.

[30] S. Kagaya, H. Miyazaki, Y. Inoue, T. Kato, H. Yanai, W. Kamichatani, T. Kajiwara, M. Saito, K. Tohda, Chelating fibers prepared with a wet spinning technique using a mixture of a viscose solution and a polymer ligand for the separation of metal ions in an aqueous solution, J. Hazard. Mater. 203-204 (2012) 370-373.

[31] Z. Li, Y. Kong, Y. Ge, Synthesis of porous lignin xanthate resin for $\mathrm{Pb}^{2+}$ removal from aqueous solution, Chem. Eng. J. 270 (2015) 229-234. 
[32] W. Peng, Z. Xie, G. Cheng, L. Shi, Y. Zhang, Amino-functionalized adsorbent prepared by means of $\mathrm{Cu}$ (II) imprinted method and its selective removal of copper from aqueous solutions, J. Hazard. Mater. 294 (2015) 9-16.

[33] Z. Lou, J. Wang, X. Jin, L. Wan, Y. Wang, H. Chen, W. Shan, Y. Xiong, Brown algae based new sorption material for fractional recovery of molybdenum and rhenium from wastewater, Chem. Eng. J. 273 (2015) 231-239.

[34] M. Sayın, M. Can, M. İmamoğlu, M. Arslan, 1,3,5-Triazine-pentaethylenehexamine polymer for the adsorption of palladium (II) from chloride-containing solutions, React. Func. Poly. 88 (2015) 31-38.

[35] T.S. Anirudhan, J.R. Deepa, Binusreejayan, Synthesis and characterization of multi-carboxyl-functionalized nanocellulose/nanobentonite composite for the adsorption of uranium(VI) from aqueous solutions: Kinetic and equilibrium profiles, Chem. Eng. J. 273 (2015) 390-400.

[36] Y.-S. Ho, Selection of optimum sorption isotherm, Carbon. 42 (2004) 2115-2116.

[37] M.R. Awual, M.A. Shenashen, T. Yaita, H. Shiwaku, A. Jyo, Efficient arsenic(V) removal from water by ligand exchange fibrous adsorbent, Water Res. 46 (2012) 5541-5550.

[38] K.Y. Foo, B.H. Hameed, Insights into the modeling of adsorption isotherm systems, Chem. Eng. J. 156 (2010) 2-10.

[39] B. Liu, X. Lv, X. Meng, G. Yu, D. Wang, Removal of Pb(II) from aqueous solution using dithiocarbamate modified chitosan beads with $\mathrm{Pb}(\mathrm{II})$ as imprinted ions, Chem. Eng. J. 220 (2013) 412-419.

[40] L. Dominguez, Z. Yue, J. Economy, C.L. Mangun, Design of polyvinyl alcohol mercaptyl fibers for arsenite chelation, React. Func. Poly. 53 (2002) 205-215.

[41] K.R. Bandi, A.K. Singh, A. Upadhyay, Electroanalytical and naked eye determination of $\mathrm{Cu}^{\left({ }^{2+}\right)}$ ion in various environmental samples using 5-amino-1,3,4-thiadiazole-2-thiol based Schiff bases, Mater. Sci. Eng.: C. 34 (2014) 149-157.

[42] M. Anbia, R. Dehghan, Functionalized CMK-3 mesoporous carbon with 2-amino-5-mercapto-1,3,4-thiadiazole for $\mathrm{Hg}(\mathrm{II})$ removal from aqueous media, J. Enviro. Sci. 26 (2014) 1541-1548.

[43] Q.S. Liu, P. Wang, S.S. Zhao, W. Zhang, Treatment of an industrial chemical waste-water using a granular activated carbon adsorption-microwave regeneration process, J. Chem. Technol. and Biotechnol. 87 (2012) 1004-1009.

[44] Q.-S. Liu, T. Zheng, P. Wang, L. Guo, Preparation and characterization of activated carbon from bamboo by microwave-induced phosphoric acid activation, Industrial Crops and Products. 31 (2010) 233-238.

[45] Q.-S. Liu, T. Zheng, N. Li, P. Wang, G. Abulikemu, Modification of bamboo-based activated carbon using microwave radiation and its effects on the adsorption of methylene blue, Appl. Surf. Sci. 256 (2010) 3309-3315.

[46] Y. Yang, P. Wang, Y. Liu, Species distribution of ferric hydrolysates in microwave enhanced Fenton-like process and possible mechanism, J. Hazard. Mater. 178 (2010) 293-297.

[47] C. Luo, J. Wang, P. Jia, Y. Liu, J. An, B. Cao, K. Pan, Hierarchically structured polyacrylonitrile nanofiber mat as highly efficient lead adsorbent for water treatment, Chem. Eng. J. 262 (2015) 775-784.

[48] L. Zhang, X. Zhang, P. Li, W. Zhang, Effective $\mathrm{Cd}^{2+}$ chelating fiber based on polyacrylonitrile, React. Func. Poly. 69 (2009) 48-54. 
[49] R. Qu, X. Sun, C. Sun, Y. Zhang, C. Wang, C. Ji, H. Chen, P. Yin, Chemical modification of waste poly(p-phenylene terephthalamide) fibers and its binding behaviors to metal ions, Chem. Eng. J. 181182 (2012) 458-466.

[50] G.R. Kiani, H. Sheikhloie, N. Arsalani, Heavy metal ion removal from aqueous solutions by functionalized polyacrylonitrile, Desalination. 269 (2011) 266-270.

[51] D. Liu, Z. Li, Y. Zhu, Z. Li, R. Kumar, Recycled chitosan nanofibril as an effective $\mathrm{Cu}(\mathrm{II}), \mathrm{Pb}(\mathrm{II})$ and $\mathrm{Cd}(\mathrm{II})$ ionic chelating agent: Adsorption and desorption performance, Carbohydr. Polymers. 111 (2014) 469-476.

[52] L.V.A. Gurgel, L.F. Gil, Adsorption of $\mathrm{Cu}(\mathrm{II}), \mathrm{Cd}(\mathrm{II})$, and $\mathrm{Pb}(\mathrm{II})$ from aqueous single metal solutions by succinylated mercerized cellulose modified with triethylenetetramine, Carbohydr. Polymers. 77 (2009) 142-149. 